\title{
Dynamic response of full-scale sandwich composite structures subject to air-blast loading
}

\author{
H. Arora, P. Hooper and J. P. Dear \\ Department of Mechanical Engineering, Imperial College London, SW7 2AZ
}

\begin{abstract}
Glass-fibre reinforced polymer (GFRP) sandwich structures $(1.6 \mathrm{~m} \times 1.3 \mathrm{~m}$ ) were subject to 30 $\mathrm{kg}$ charges of $\mathrm{C} 4$ explosive at stand-off distances 8-14 m. Experiments provide detailed data for sandwich panel response, which are often used in civil and military structures, where airblast loading represents a serious threat. High-speed photography, with digital image correlation (DIC), was employed to monitor the deformation of these structures during the blasts. Failure mechanisms were revealed in the DIC data, confirmed in post-test sectioning. The experimental data provides for the development of analytical and computational models. Moreover, it underlines the importance of support boundary conditions with regards to blast mitigation. These findings were analysed further in finite element simulations, where boundary stiffness was, as expected, shown to strongly influence the panel deformation. In-depth parametric studies are ongoing to establish the hierarchy of the various factors that influence the blast response of sandwich composite structures.
\end{abstract}

Keywords: Layered structures, Polymer-matrix composites (PMCs), Impact behaviour, Finite element analysis (FEA)

\section{Introduction}

Glass-fibre reinforced polymer (GFRP) composites are often used in the construction of naval structures as well as carbon and various new polymer fibre hybrids. These materials can be subject to increasingly demanding and varied conditions during service. In a military context, blast loads represent the most extreme threat to a structure. The research presented in this paper focuses on air-blast loading of GFRP sandwich composite panels and the initial finite element modelling of these air-blast conditions.

Several studies have investigated the dynamic deformations due to explosive blast loading on plates. Menkes and Opat [1] classified failure modes of structures under impulse loading, from large inelastic deformation to tearing and shear failure at the supports. Nurick amongst others has conducted extensive studies over the years investigating various plate response to blast loading summarised in Ref. [2]. For instance the types of failures described by Menkes and Opat have been investigated further by Nurick, Olsson et al. [3], in particular the significant effects of the boundary conditions for the purpose of predicting tearing in steel plates have been highlighted in Ref. [4]. Cantwell, Nurick and Langdon et al. have continued similar experimental investigations and analysis into composite behaviour under blast conditions [5, 6, 7]. In addition to explosive testing, shock tubes have been found to give a good and convenient option for shock/blast studies. 
Tekalur et al. $[8,9,10]$ have experimentally studied the effect of blast loading using shock tubes and controlled explosion tubes loading on E-glass fibre based composites and other materials. Results suggested that the E-glass fibre composite experienced progressive damage during highrate loading of the same nature as described in Hoo Fatt and Palla [11], with progressive front face failure due to indentation followed by complete core collapse. These studies have been continually developed by the same research group to great effect, with many parameters being examined such as the distribution of blast energy during the impact process [12] and retention of integrity of sandwich structures due to blast loads [13].

\section{Materials}

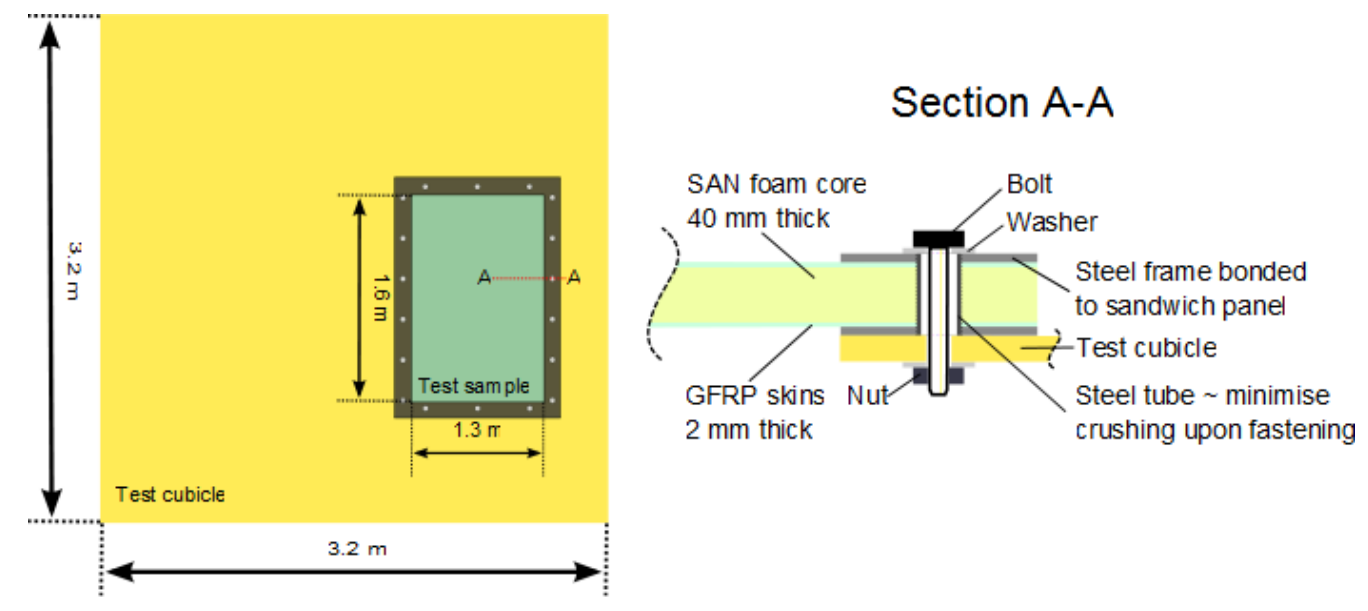

Figure 1: Schematic of sandwich panel construction and mounting fixture.

GFRP sandwich composite panels were the chosen targets to be tested, shown schematically in Figure 1. Sandwich panels, provided by SP Gurit manufactured by P.E. Composites, were constructed using 2 plies of $\left(0^{\circ} / 90^{\circ} \% 45^{\circ}\right)$ E-glass quadriaxial skins (manufacturer code: $\mathrm{QE} 1200$ ) on a $40 \mathrm{~mm}$ thick SAN foam core (manufacturer code: P800) infused with a Prime-LV epoxy resin. A summary of the properties of the skin and core materials obtained from the sample manufacturers are given in Table 1. The exposed target area for the air-blast experiments was 1.6 $\mathrm{m} \times 1.3 \mathrm{~m}$. These large panels were designed to represent full-scale face-panels of comparable scale to real naval structures. These targets were bonded into steel frames prior to testing, ready to be mounted into the test cubicle as shown in Figure 1.

\section{Experimental}

\subsection{Air blast test design}

GFRP sandwich panels were subject to full-scale air-blast loading (30 kg C4) to observe the deformation and damage development within such typical marine constructions. The test samples were designed to withstand a peak reflected overpressure, $P_{\max }$, of 2 bar without catastrophic failure. Methods used to design these structures involved both analytical and computational methods. A finite element model was generated in ABAQUS/Explicit 6.10. Initially 


\begin{tabular}{|c|c|c|}
\hline Material property & QE1200 & P800 \\
\hline Density $\left(\mathrm{kg} / \mathrm{m}^{3}\right)$ & 1750 & 155 \\
\hline Tensile modulus (GPa) & 17 & 0.14 \\
\hline Compressive modulus (GPa) & - & 0.13 \\
\hline Tensile strength (MPa) & 260 & - \\
\hline Compressive strength (MPa) & 200 & 2.8 \\
\hline Shear modulus (MPa) & 6500 & 61 \\
\hline Tensile failure strain $(\%)$ & 1.5 & - \\
\hline
\end{tabular}

a 3D solid continuum element model was generated with the plate geometry sectioned into its composite constituent layers. This model was then simplified to a shell element model for computational efficiency. Correlation of in-plane surface strains and peak deflection between the 3D solid continuum element model and shell element model was strong, therefore future work proceeded with the shell model for this investigation. This model comprised of a continuum shell element model sectioned into the various layers of the sandwich composite (i.e. skin and core) with the material properties (density and Young's modulus) as given in Table 1. This was then subject to a triangular pressure pulse, with zero rise-time to $P_{\max }=2$ bar, uniformly distributed over the entire plate with a linear decay time of $5 \mathrm{~ms}$. It was shown that using a simple elastic material model and reducing the load conditions to a uniform pressure pulse with ideal fully clamped boundary conditions that the plates (configuration as shown in Figure 1) would produce a peak central displacement in the region of $45-65 \mathrm{~mm}$ for targets with a range of core thicknesses of $30-50 \mathrm{~mm}$ (producing strains in the GFRP below their expected failure strains $\sim 1.5 \%)$. Based on this model a series of targets were designed and various blast scenarios were tested. The two presented relate to $40 \mathrm{~mm}$ thick core targets. The blast parameters used during the tests presented in this paper were as follows: $30 \mathrm{~kg} \mathrm{C} 4$ charge at $8 \mathrm{~m}$ and $14 \mathrm{~m}$ stand-offs. The experiments conducted for a $30 \mathrm{~kg}$ charge at a $14 \mathrm{~m}$ stand-off distance, i.e. an equivalent $P_{\max }$ of $\sim 2$ bar, were designed in line with the above model whereas the $30 \mathrm{~kg}$ charge at $8 \mathrm{~m}$ was designed with the intent to cause significant visible damage.

\subsection{Instrumentation}

A summary of the experimental configuration is shown in Figure 2 including a top-down view of the test pad in Figure 2(a). Full-field displacement plots of the back face of the target were obtained for the duration of the blast event by employing high-speed photography in conjunction with digital image correlation (DIC) methods. Two high-speed video cameras (Photron SA3s) were positioned behind the $1.6 \mathrm{~m} \times 1.3 \mathrm{~m}$ speckled targets (black speckles on a matte white background applied to the rear face) and sampled at $2000 \mathrm{fps}$ at full resolution (1024 x 1024 pixels). This sampling frequency was chosen based on the FE model described earlier crossreferenced with analytical modeling based on the approach outlined in Biggs [15]. Using the Photron SA3 cameras it was possible to operate at full resolution (keeping spatial resolution high i.e. detail of analysis), whilst capturing the images at a suitable rate for the DIC analysis to be conducted with sufficient temporal resolution. These cameras, housed in a purpose built test cubicle featured in Figure 2(b), were then calibrated to allow the recorded images to be processed in ARAMIS, the DIC software used to conduct the image correlation (produced by $\mathrm{GOM} \mathrm{mbH}$ ). For verification purposes, a laser gauge was positioned on a steel beam mount as 
a secondary point displacement measurement device focussing on the centre of the panel. The results will feature in the results section as a comparison to the DIC data. Note that in each image shown the gauge and gauge mount will remain visible. Reflected pressure and incident (side-on) pressure measurements were taken at the same stand-off distance from the charge as the target. High-speed video cameras were also positioned externally on the test pad, shielded in turrets, to capture front-face deformation as shown in Figure 2(a).
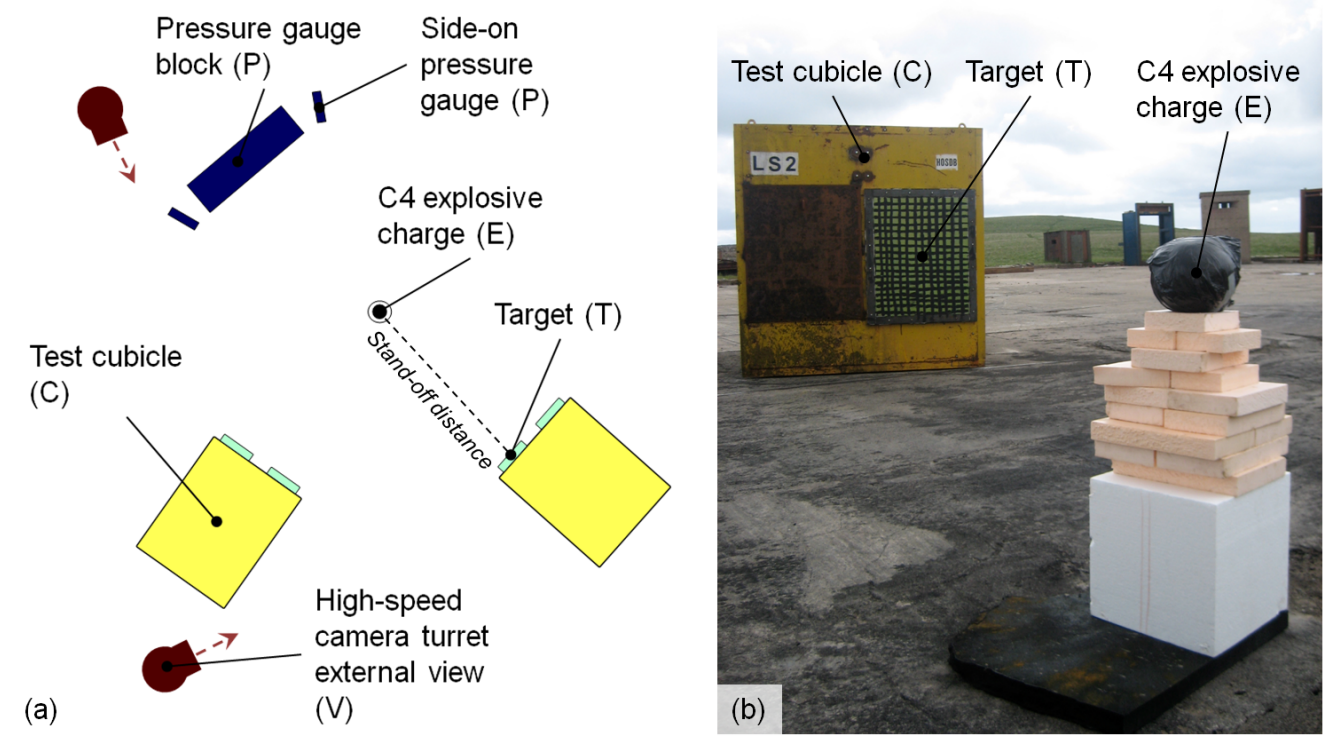

Figure 2: Blast configuration: (a) Schematic diagram and (b) image of the test set-up. Featured in each diagram are: Target to be tested (T), test cubicle (C), high-speed camera and its relative location on the test pad (V), pressure sensor arrangements $(\mathrm{P})$ and $\mathrm{C} 4$ explosive charge (E).

\section{Results}

\subsection{Air blast of GFRP sandwich composite panels}

The first target was subject to the $30 \mathrm{~kg} \mathrm{C} 4$ explosive charge at a $14 \mathrm{~m}$ stand-off distance. Figure 3 illustrates the magnitude of the blast event with sample images taken by the high-speed cameras positioned on the test pad, which capture the shock wave impinging on the test structure. The shock wave is seen to arrive at the target $20 \mathrm{~ms}$ after detonation. This blast scenario was designed to take the panels to their elastic limit as stated in the Section 3.1, therefore no visible blast damage effects are observed on the front face.

Figure 4 shows a summary of the data recorded for this blast (30 kg C4 at $14 \mathrm{~m}$ stand-off). The figure shows central out-of-plane displacement (taken by the two measurement techniques: DIC and laser gauge) of the target sandwich panel with the pressure-time trace overlaid. Contour plots support the graphical data taken from the DIC analysis of the rear face of the sandwich composite panel, shown for the period highlighted in the figure. Note in the contour plots there is a visible bar across the centre of the contour plots, this is the laser gauge and its mount which obscures DIC analysis of the target being conducted for that region. The sets of data presented 


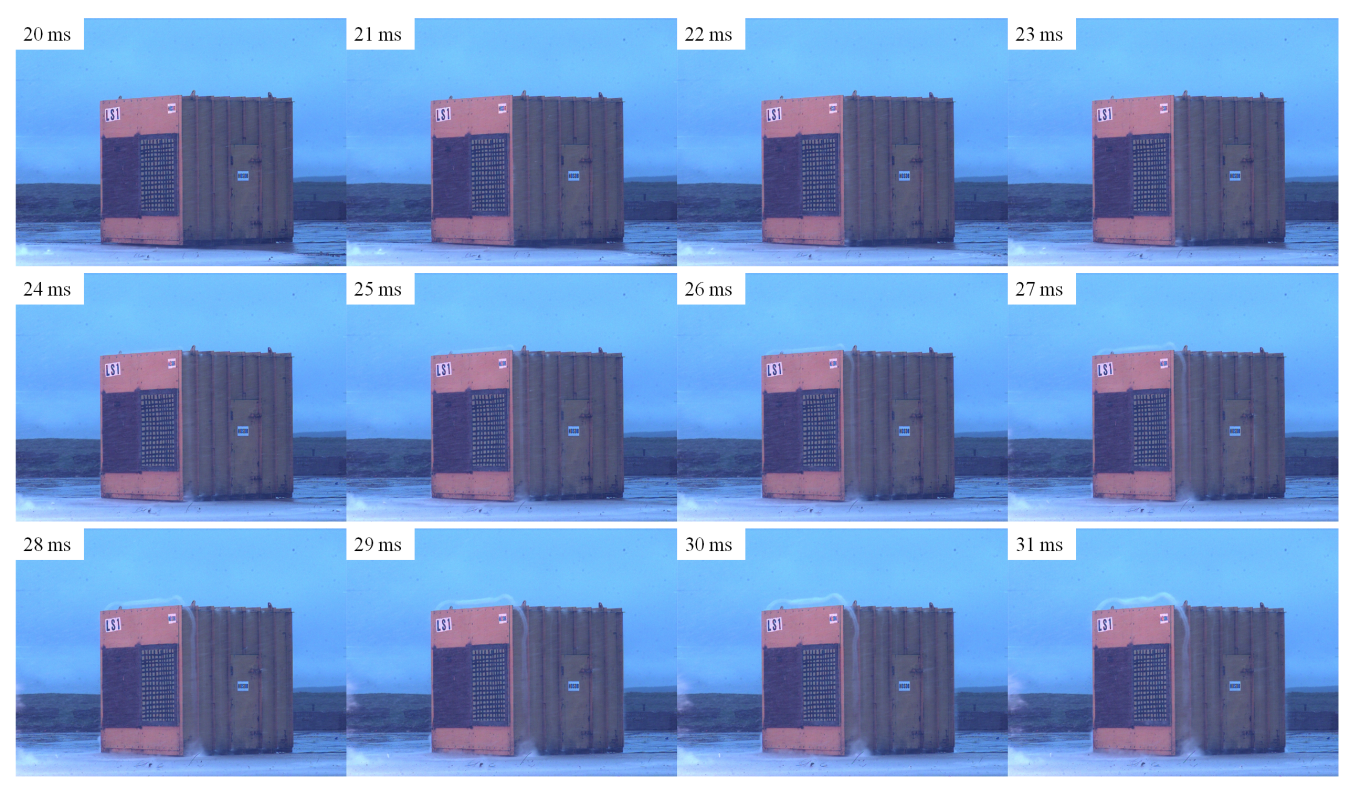

Figure 3: Images of shock wave progression and front-face deformation. Images are shown from shock wave arrival at target $(20 \mathrm{~ms})$ until target's first rebound $(31 \mathrm{~ms})$.

in this paper are given over regular time intervals to show the full range of behaviour of the test samples under blast conditions. This enables detailed interpretations of the response and aids the modelling process of such events.

The plot in Figure 4(b) helps to characterise the blast in terms of the target response relative to its loading. The regime of this test can be referred to as dynamic, given the comparison of the time to peak displacement and the first positive phase of pressure loading [16]. This agrees with the fact that this blast scenario was designed to keep the deformation elastic (as truly impulsive load conditions generally lead to damage development in such structures). The coloured contour plots shown in Figure 4(a) show the transient response of the target with respect to out-of-plane displacement $\left(U_{z}\right)$ of the rear face, in-plane maximum principal strain $\left(\epsilon_{\max }\right)$ and shear strain $\left(\epsilon_{x y}\right)$. The contour plots all indicate a uniform and symmetrical response across the panel up until maximum out-of-plane displacement $U_{z}^{\max }$ is reached. Shear strain plots remained symmetrical about the $x-y$ line indicating a uniform deformation and the strain magnitudes remained relatively low below $0.5 \%$ due to the relatively small deflections experienced in comparison to the panel size for this blast condition. The displacement, principal strain and shear strain all show an essentially symmetrical response until $U_{z}^{\max }$ but beyond this condition there is a deviation from this behaviour. There is a slight non-uniformity in the loading on the front face. This is due to the shock wave interaction with the structure (panel and test cubicle) and ground reflections, resulting in higher initial pressures towards the base. However the global response of the panel, after the first millisecond, takes on the expected symmetrical shapes. This is the case until the first rebound beyond which asymmetry in the supports (boundary conditions) influences the deformation profile strongly (to be discussed later in section 6.1). Figure 4(b) shows the transient central point deflection of the panel subjected to a recorded $P_{\max }=2$ bar, positive phase duration, $\tau_{d},=6.3 \mathrm{~ms}$, (30 kg of C4 at stand-off of $\left.14 \mathrm{~m}\right)$. The target was seen to deflect to 


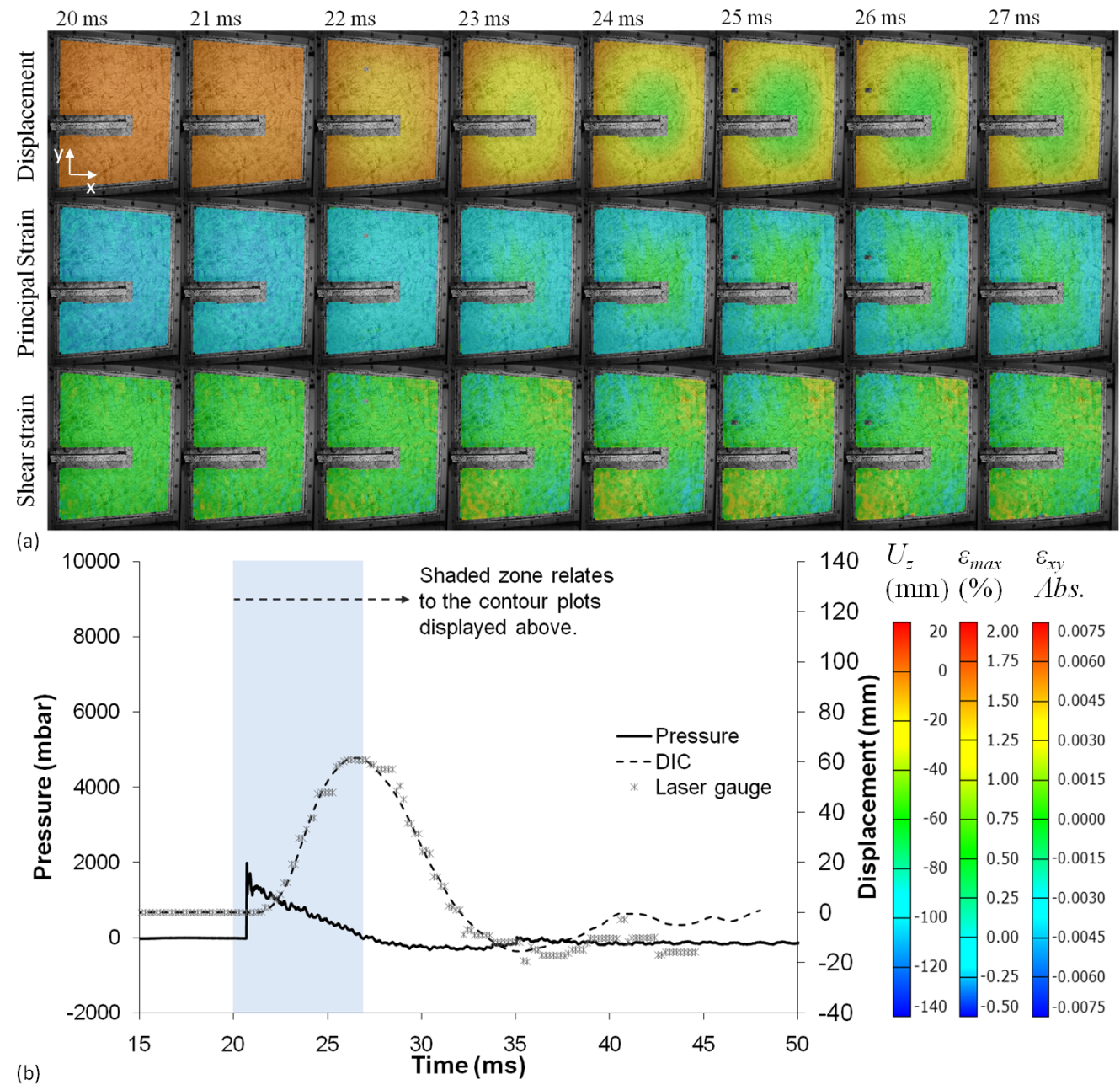

Figure 4: Blast summary for $30 \mathrm{~kg} \mathrm{C4}$ at $14 \mathrm{~m}$ stand-off including: (a) DIC analysis and (b) a plot of pressure-time and displacement-time using both DIC and laser gauge centre point measurements. The DIC analyses features contour plots of out-of-plane displacement, maximum principal strain and shear strain, corresponding to various stages in the graphical plot. The horizontal bar visible in the contour plots (from the left hand edge to the centre) is the region of the specimen obscured by the laser gauge.)

a maximum distance out-of-plane $\left(U_{z}^{\max }\right)$ of $63 \mathrm{~mm}$. The laser gauge data correlated well with DIC analysis for centre point measurement up until the point of maximum deflection. After this point, vibrations caused the mount to flex and hence measurements from the laser gauge became compromised. The photography and hence DIC data was deemed reliable until after the first rebound. After this point, appreciable vibrations transmit through the isolation mounts to the camera arrangement, affecting the relative positions and orientation of the cameras compared to their original positions (visible in the images). Therefore the quality of the DIC data is also compromised after this point. Strains in particular $\epsilon_{\max }$ peaked at $\sim 1 \%$ on the back face, as observed in Figure 4. The panel was deformed within a limit such that no visible damage was sustained. 
This agreed with observations taken in the DIC analysis of the $\epsilon_{\max }$ fields compared to material properties highlighted in Table 1, which stated that strains below $1.5 \%$ would not result in skin failure (fibre breakage). There was no evidence of damage shown by the DIC analysis in terms of either magnitude or distribution of strain.

The DIC results agreed well with predictions for peak elastic displacements of the targets due to a $P_{\max }=2$ bar $\left(\tau_{d}=6.3 \mathrm{~ms}\right)$. It was then decided that another panel of the same construction be subject to a more substantial blast to induce significant skin and core damage, to evaluate the damage detection capabilities of this technique (DIC). Blast parameters for this final air blast involved a $30 \mathrm{~kg}$ charge positioned at a reduced stand-off of $8 \mathrm{~m}$ from the target.

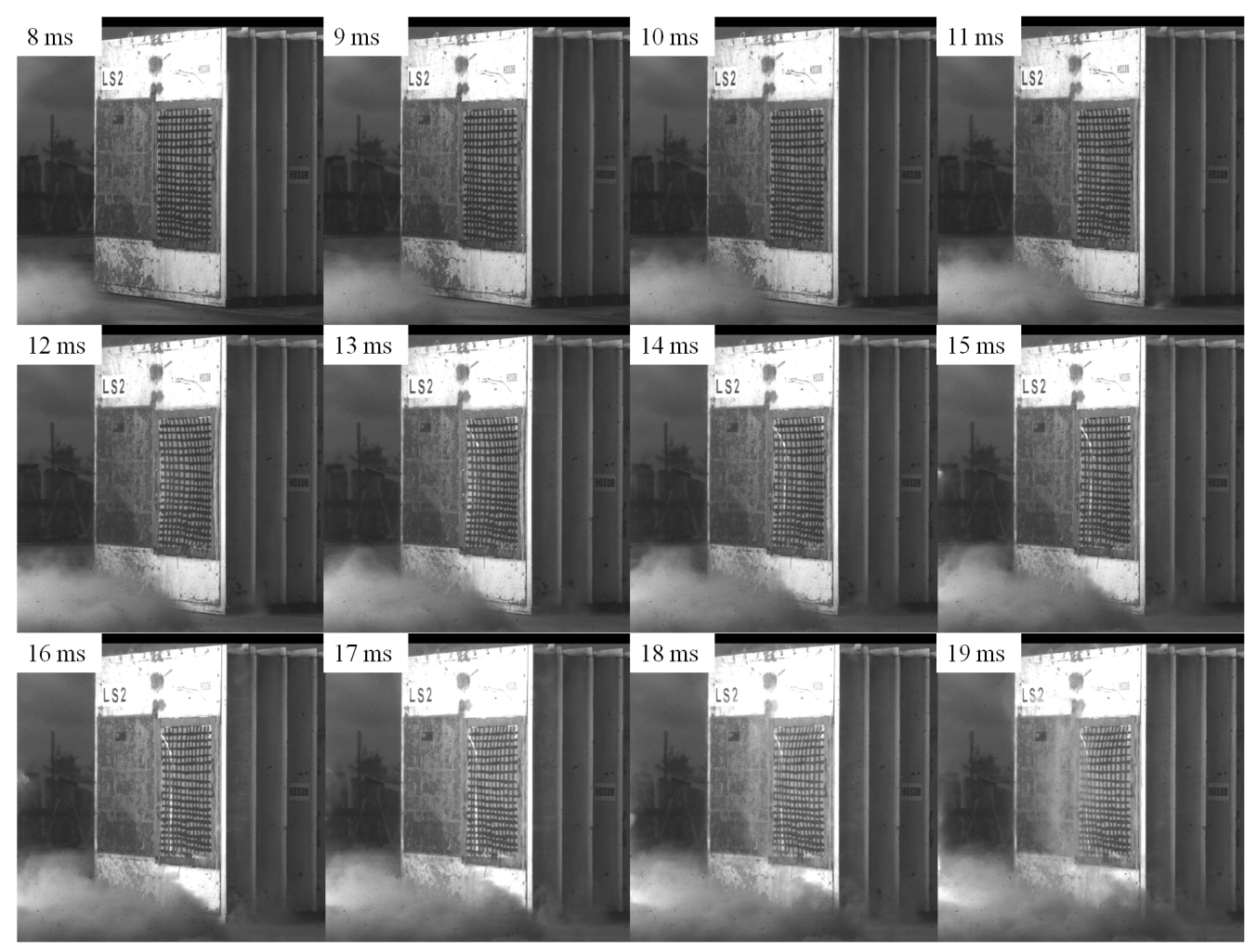

Figure 5: Images of shock wave progression and front-face deformation. Images are shown from shock wave arrival at target (8 ms) until target's first rebound $(19 \mathrm{~ms})$.

Figure 5 shows the progressive deformation and eventual skin damage inflicted on the panel by the blast, where $P_{\max }=8$ bar; $\tau_{d}=5.7 \mathrm{~ms}$, corresponding to a $30 \mathrm{~kg}$ charge C 4 at $8 \mathrm{~m}$ stand-off. A skin crack is seen to originate from the top left hand edge of the panel $13 \mathrm{~ms}$ into the blast event and propagate down that side of the target. Figure 6 shows a summary of the blast data recorded for this blast ( $30 \mathrm{~kg} \mathrm{C} 4$ at $8 \mathrm{~m}$ stand-off). The figure shows central out-of-plane displacement of the target sandwich panel, $40 \mathrm{~mm}$ core, and the pressure-time trace overlaid alongside DIC data as shown before for the blast at $14 \mathrm{~m}$ stand-off. However when comparing this graphical plot of out-of-plane displacement in Figure 6(b) to that shown earlier in Figure 4(b), in addition to the magnitude of $U_{z}^{\max }$, immediately one can notice the difference in smoothness of the path 


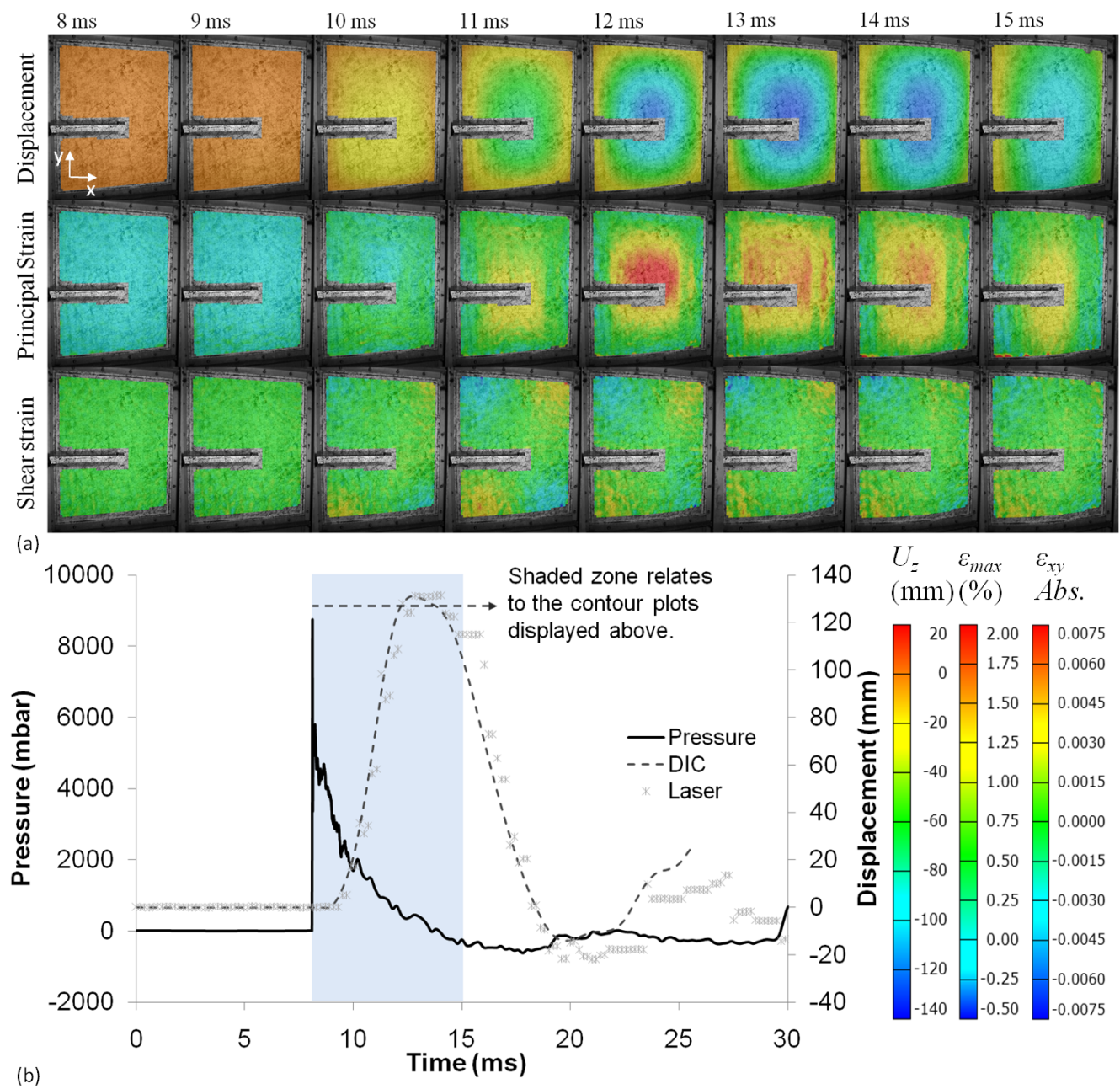

Figure 6: Blast summary for $30 \mathrm{~kg} \mathrm{C} 4$ at $8 \mathrm{~m}$ stand-off including: (a) DIC analyses and (b) a plot of pressure-time and displacement-time using both DIC and laser gauge centre point measurements. The DIC analyses features contour plots of out-of-plane displacement, maximum principal strain and shear strain, corresponding to various stages in the graphical plot. 


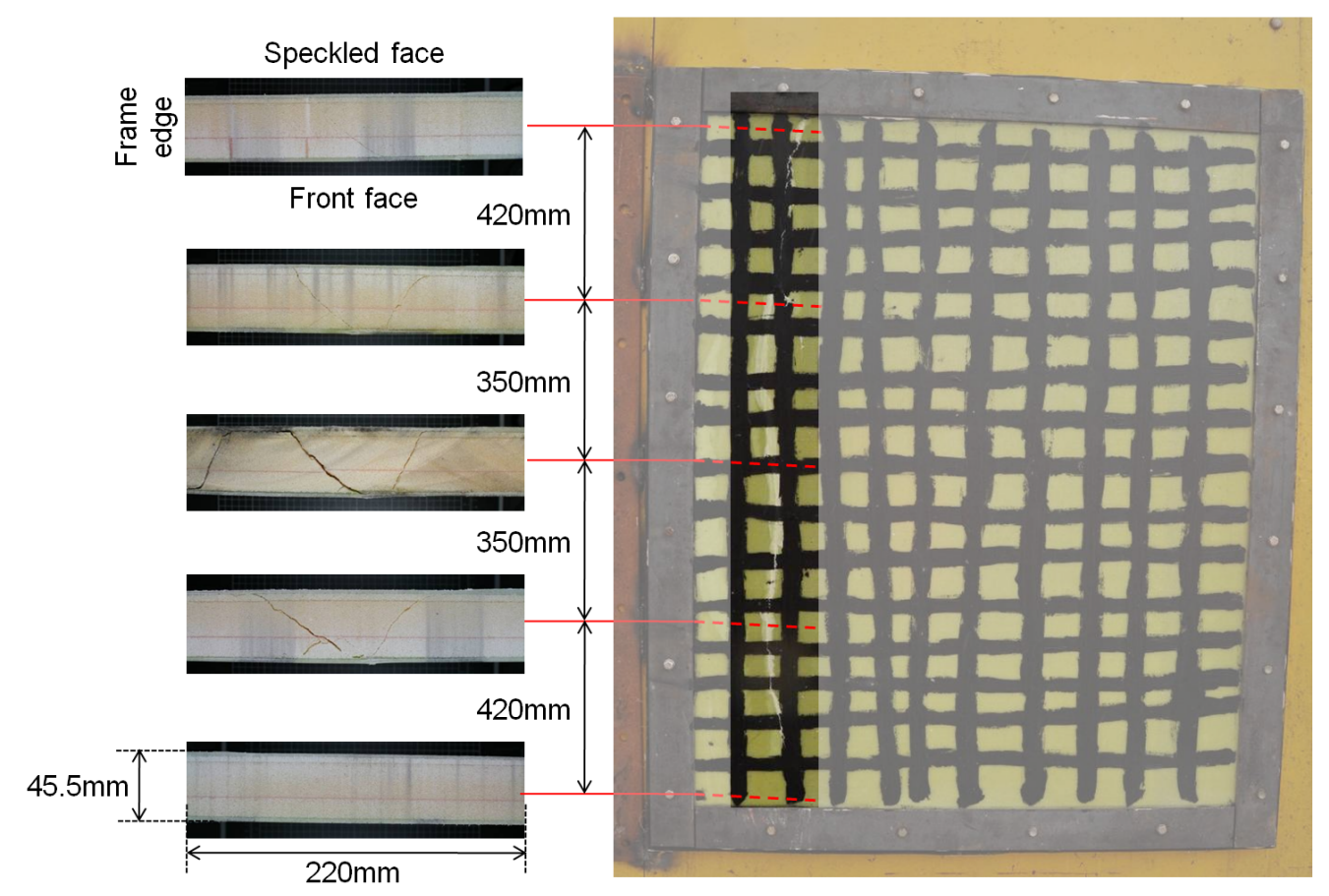

Figure 7: Front face damage of the target subject to a charge of $30 \mathrm{~kg}$ charge at stand-off of $8 \mathrm{~m}$ : The whole panel with a clear crack down the left-hand edge of the panel (right), sectioned at regular intervals showing various failure mechanisms present in the highlighted region of the panel (left).

(DIC) taken during the first period of oscillation. Looking closely at the time period $12.5-14.0$ $\mathrm{ms}$, one can observe a flattening in the displacement curve near its maximum. This coincides with the time $\left(13 \mathrm{~ms}\right.$ ) when the crack is observed to form in Figure 5. $U_{z}^{\max }$ was found to be $131 \mathrm{~mm}$. There was again good agreement between the laser gauge data and the DIC data until $U_{z}^{\max }$ was reached. $\epsilon_{\max }$ peaked in the region of $\sim 3 \%$ prior to the crack developing. Upon post inspection, the front face sustained inter-laminar skin failure and front-ply fibre breakage whilst the core suffered cracking from skin to skin but the rear skin remained intact (see Figure 7). The severity of the failure increased towards the centre of the panel.

\section{Finite element modelling of air-blast}

The experimental results showed in the raw images, highlighted with the DIC analysis, that the boundary conditions during a shock event are not guaranteed to be constant throughout from start to finish. The test cubicle is purpose built for blast experimentation. However, no matter how rigid the support structure is, especially in real or commercial marine structures, there will naturally be a degree of elasticity present. This elasticity will affect the response of the target panel (structure). Therefore finite element simulations were generated to take these effects into account modelling the response of the target sandwich panel held within the steel test cubicle. Two main models will be presented to illustrate the comparability of various restraint conditions. ABAQUS/Explicit 6.10 was used to generate the various models. There are other effects which 
should be recognised and can be included in the models to improve the details of the analysis. such as, the non-uniformity of the pressure distribution arising from target geometry and ground reflections. The pressure distribution was studied using computational fluid mechanics analysis. These, however, have been omitted from this study as the focus is the influence of the boundary conditions and this is seen to be the most significant factor influencing the panel response.

\subsection{Air blast test design - model evolution}

Initially the analysis focused on the design of the test cubicle structure as a whole. The model was reduced to a simple shell element model with the test cubicle front and sandwich composite structure partitioned within the single part, shown in Figure 8. The material properties used were as for the materials introduced in the previous experimental section in Table 1(skin density, $\rho_{s}$, $1752 \mathrm{~kg} / \mathrm{m}^{3}$, Young's modulus skin, $E_{s}, 17.2 \mathrm{GPa}$, core density, $\rho_{c}, 155 \mathrm{~kg} / \mathrm{m}^{3}$, Young's modulus core, $E_{c}, 138 \mathrm{MPa}$ ) and the mild steel was taken to have properties as follows: density, $\rho_{\text {steel }}$, $7800 \mathrm{~kg} / \mathrm{m}^{3}$ and Young's modulus, $E_{\text {steel }}, 208 \mathrm{GPa}$. The sandwich composite target was assigned composite continuum shell elements, allowing the sandwich lay-up to be created. The steel cubicle front was simplified to homogeneous continuum shell elements. To simplify the problem the effective stiffness of the various I-beams and ribbed plates etc were taken into account by equivalent thickness of elements for the test cubicle. Boundary conditions were fully built-in front face around the edges of the cubicle, assuming no movement (no slip) of the entire cubicle structure during the blast.
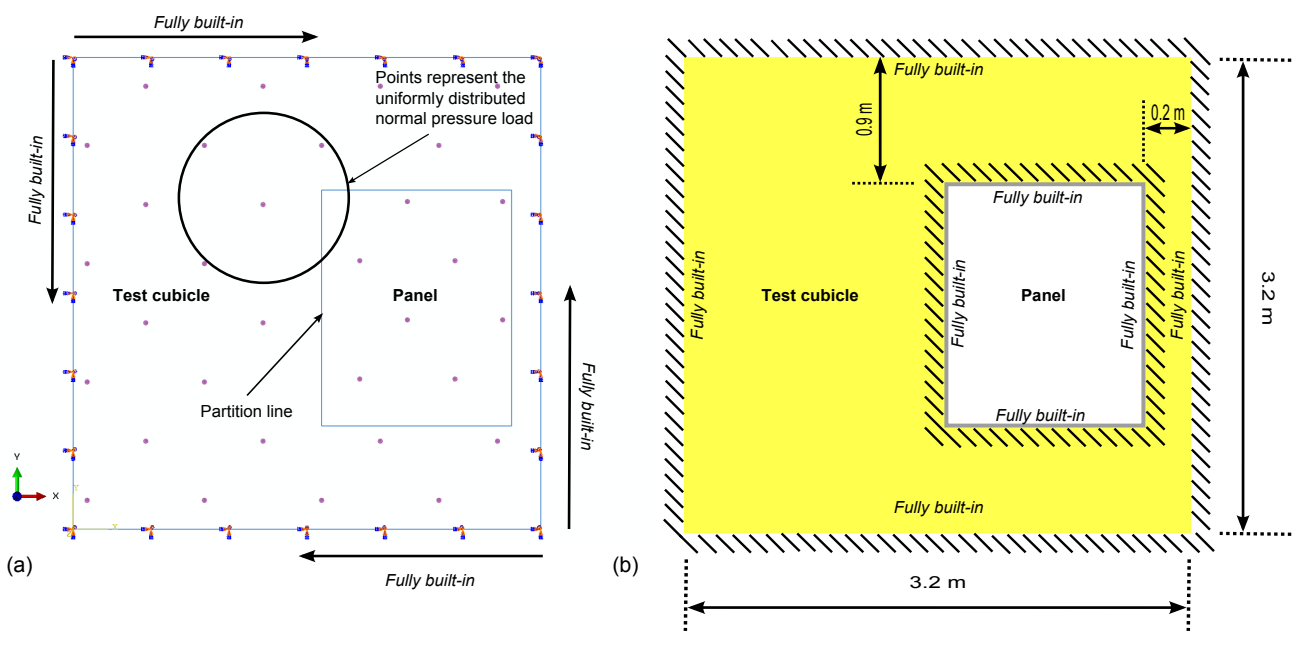

Figure 8: Boundary and load conditions: (a) An annotated ABAQUS visualisation of the model consisting of one part partitioned into the sandwich composite panel and the steel front of the test cubicle; and (b) A schematic representation of the same model highlighting the effective boundary conditions on the sandwich composite and the test cubicle front.

The boundary conditions at the sandwich panel edge were effectively built-in to the cubicle structure, taking into account movements in the boundary (of the plate). The load applied is taken as the experimentally recorded reflected pressure for each blast scenario. This was applied as a uniformly distributed transient pressure loading (highlighted in Figure 8(a)). The $P_{\max }$ measured during the two blasts was 2 bar $\left(\tau_{d}=6.3 \mathrm{~ms}\right)$ and 8 bar $\left(\tau_{d}=5.7 \mathrm{~ms}\right)$ for $30 \mathrm{~kg}$ at $14 \mathrm{~m}$ and $8 \mathrm{~m}$ stand-off distances respectively. This model deviates from the ideal case (of a built-in plate) but gives a realistic representation of the support for the composite panel. 


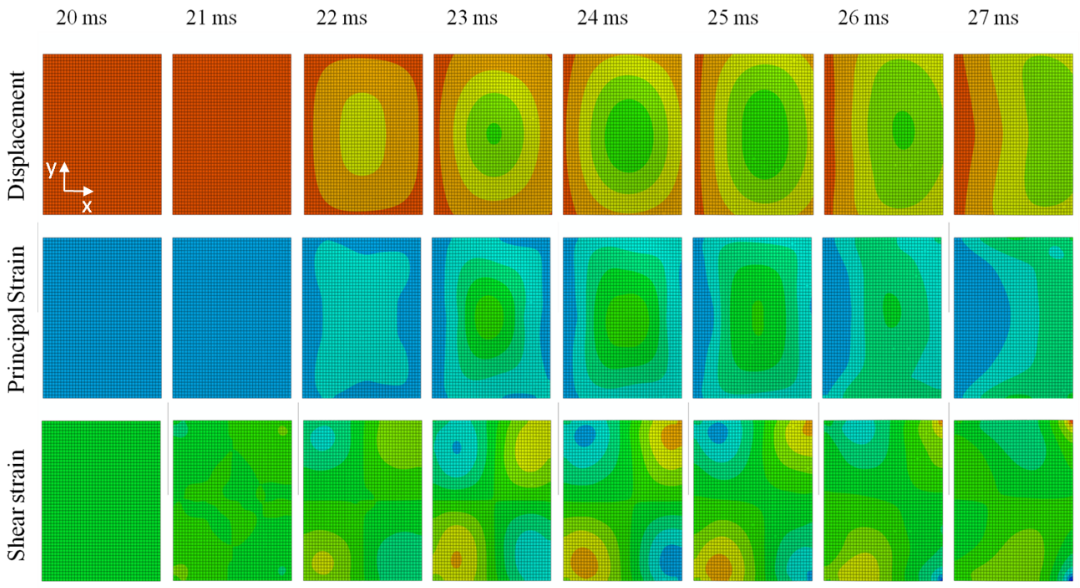

(a)

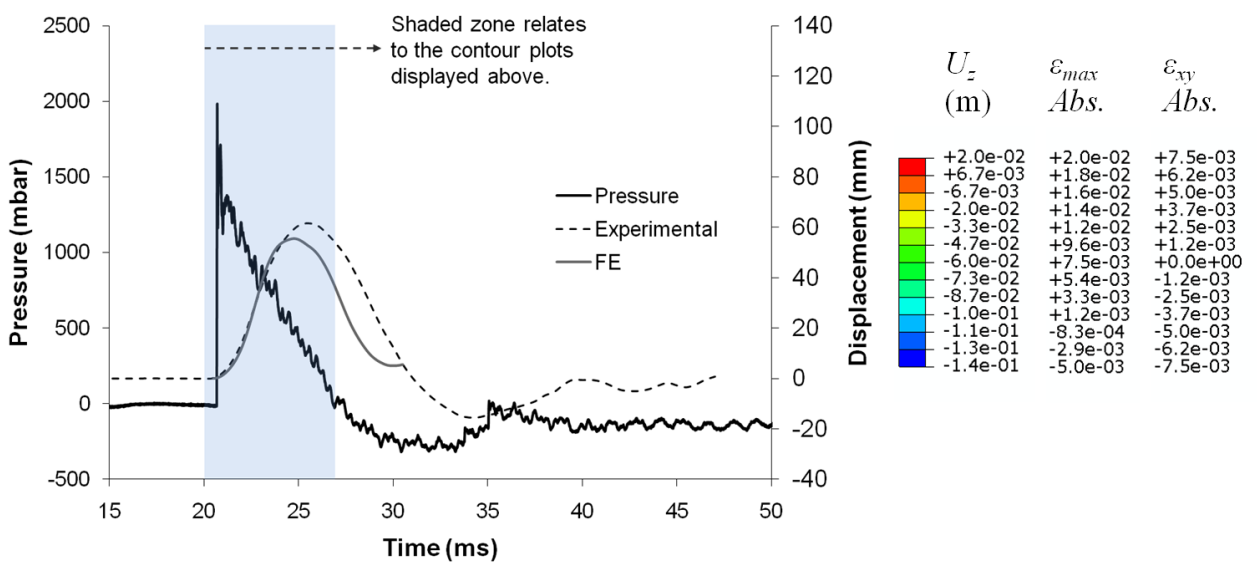

(b)

Figure 9: Blast summary, for $30 \mathrm{~kg} \mathrm{C} 4$ at $14 \mathrm{~m}$ stand-off, including FE analyses: (a) Contour plots of the composite sandwich panel's out-of-plane displacement, maximum principal strain and shear strain; and (b) a graphical plot of loadtime and displacement-time for both the FE and experimental results for comparison. Note that the contour plots shown are of the plate (composite sandwich panel) region of the model only and that they correspond to various stages in the graphical plot.

The results from this initial model firstly highlight the obvious effect of the support structure on the panel response, given it formed an asymmetrically deformed surface. Figure 9 shows the contour plots of the FE analysis displaying the transient response in terms of out-of-plane displacement, maximum principal strain and shear strain for the blast modelling $30 \mathrm{~kg}$ at $14 \mathrm{~m}$ stand-off. The contour plots displayed are just for the plate (composite sandwich panel) alone and the deformation of the front of the cubicle is omitted from the view in the figure. These images are shown alongside a graphical plot of central out-of-plane displacement against time for the FE and experimental analyses. The magnitude of the two respective peaks as well as the time period of oscillation show close but not exact agreement. This is due to the simplifications in the stiffness of the model support structure (causing the mismatch of peaks) as well as the omission of damping into the system (causing a quicker response in the model). The contour plots in 


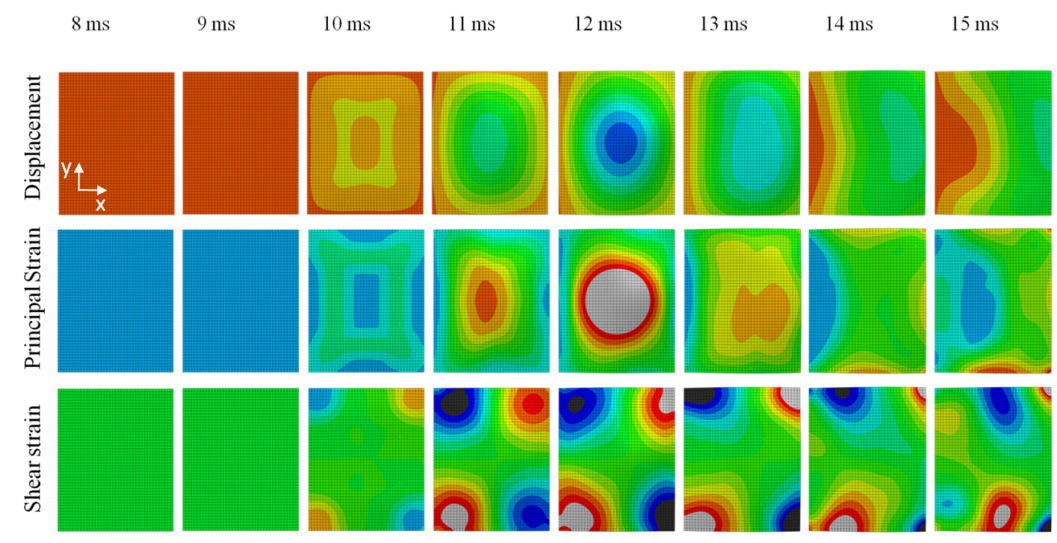

(a)

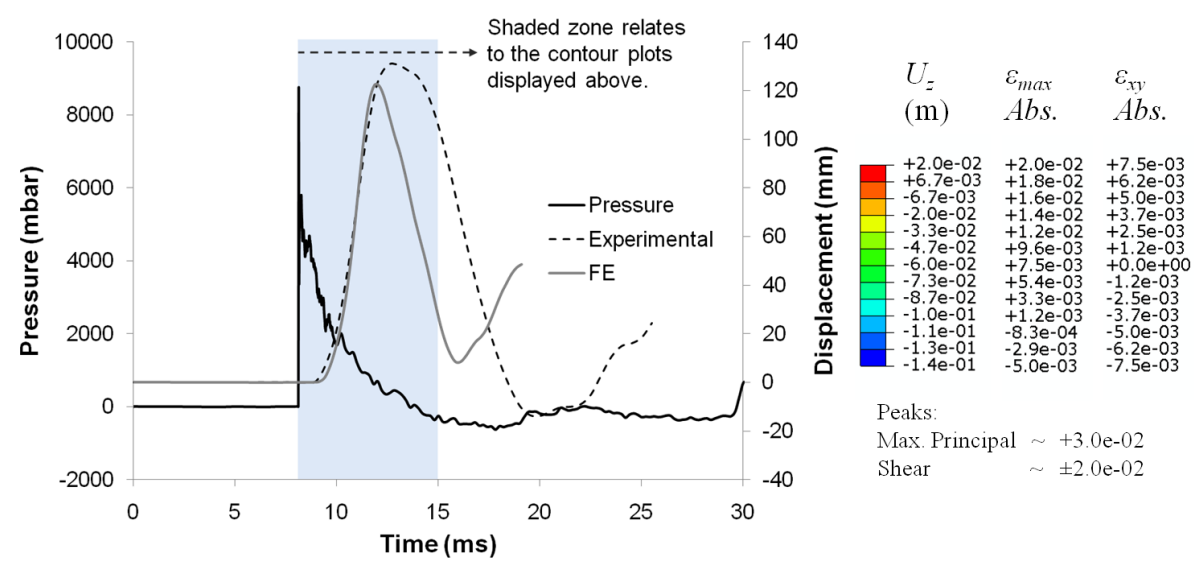

Figure 10: Blast summary, for $30 \mathrm{~kg} \mathrm{C4}$ at $8 \mathrm{~m}$ stand-off, including FE analyses: Contour plots of the composite sandwich panel's out-of-plane displacement, maximum principal strain and shear strain (a) and a graphical plot of load-time and displacement-time for both the FE and experimental results for comparison (b). The contour plots correspond to various stages in the graphical plot.

tandem with the graph of Figure 9 shows clearly that after the point of maximum displacement is reached there is a bias towards the right hand edge, causing a shift from the symmetric strain and displacement fields. The magnitude and characteristics of these contour plots correlate well to the observed experimental DIC contour plots (see Figure 4).

As the blast load is increased to $30 \mathrm{~kg}$ at $8 \mathrm{~m}$, with $P_{\max }$ raised to 8 bar $\left(\tau_{d}=5.7 \mathrm{~ms}\right)$, these effects are exaggerated, as was observed experimentally. Similar peak principal strains are observed $\sim 3 \%$ at the point of maximum deflection (see Figure 10). There is some deviation of the model from the experimental data thought to be related to the material parameters used in this analysis. The frequency of the response is higher in the model due to the lack of damping as well as the lack of plastic (damage) parameters included in the material model. In spite of these differences from the experimental data, agreement is good at capturing the global response. There is a distinct bias in terms of strain build up towards one edge with $\epsilon_{\text {max }}$ peaking in excess of $3 \%$, this is where skin failure has occurred (as evident in experimental observations). The 


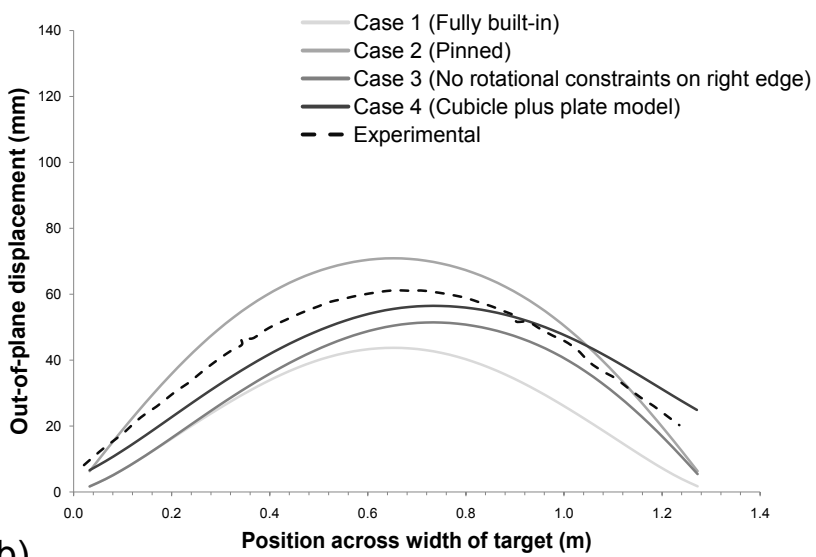

Case 2

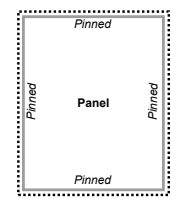

(b)

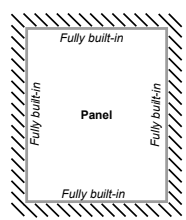

(b)

Case 3

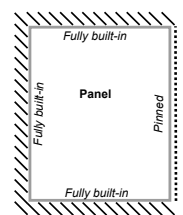

Case 4

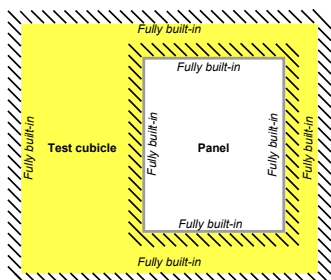

(a)

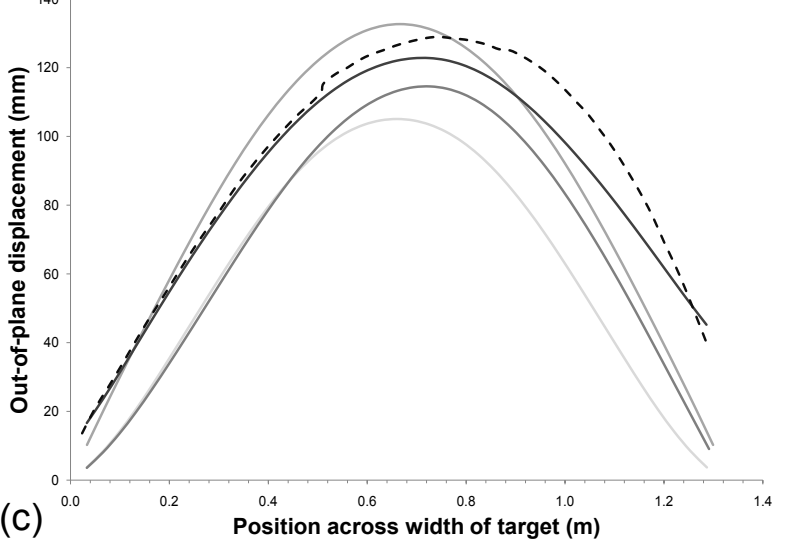

Figure 11: Summary of FE study: (a) A schematic diagram for each boundary condition tested; (b) Out-of-plane displacement plots across the central horizontal cross-section of the target when subject to $30 \mathrm{~kg} \mathrm{C4}$ at $14 \mathrm{~m}$ stand-off; and (c) $30 \mathrm{~kg} \mathrm{C} 4$ at $8 \mathrm{~m}$ stand-off. Note each profile is is shown for when the panel reaches $U_{z}^{\max }$. 
intention in this paper is to show how FE modelling can be employed to show where damage can occur during such loading conditions.

There is a significant geometrical effect and this is often the case if the blast is off-centre or if one side of a panel is less well supported than the other. Consequently a series of classic or simplified models with simple boundary conditions have been devised: Fully built-in, where there is zero translational and zero rotational degrees of freedom all around the panel edges (Case 1); Pinned, where there is zero translational degrees of freedom all around the panel edges (Case 2); and built-in on 3 edges and pinned on the right edge i.e. zero translational and zero rotational degrees of freedom all around the panel edges except the right edge, where only rotation is allowed (Case 3). Figure 11 shows a diagrammatic representation of each boundary condition (see Figure 11(a)) used alongside a summary of their respective influence on the resultant deformed profile of the target during each blast scenario investigated (see Figure 11(b-c)).

These three restraint conditions were simulated for each blast scenario. A set of the three model's results are displayed in Figure 11(b-c) for each blast scenario alongside the experimental results and the previous simulation incorporating the cubicle and panel together (denoted from now on as Case 4). The figure shows a plot of the profile across the horizontal section at the point of maximum out-of-plane displacement for each model. This shows the various effects of boundary conditions on the model output and how they correlate to the experimental data. Figure 11(b) shows the results for a $30 \mathrm{~kg}$ charge at $14 \mathrm{~m}$. It is clear that the experimentally observed result lies between the Case 2 (pinned) and Case 1 (built-in). The stiffness of the boundaries can be seen as an equivalent rotational (and translational) degree of freedom. Cases 3 and 4 show that the relative degrees of freedom from one edge to the other can cause an asymmetrically deformed shape, which leads to bias in the strain distribution. Case 3 represents the relative stiffness of each edge in the test facility, given the top and bottom edge are relatively equidistant from the cubicle edge compared to the left and right hand edges. Therefore the boundaries are treated as built-in except for the right hand edge which has more degrees of freedom. This is also observed in Figure 11(c) for the $30 \mathrm{~kg}$ blast from $8 \mathrm{~m}$ stand-off. The increased impulse exerted on the target can be seen to influence the target and support response particularly in the experimental data versus Case 4. It is clear these boundary responses are influenced heavily by the impulse applied, which causes a shift in the overlap of the two curves.

\section{Discussion and analysis}

These sandwich composite structures, although very simple in construction, provided significant resistance to air-blast loading. They were designed to sustain a pressure loading of up to 2 bar without resulting in a catastrophic failure and attained this performance. When the charge was moved in closer to the target resulting in 8 bar reflected pressure, the front face and core sustained considerable damage (core cracking, formations of delaminations and skin fibre breakage). However the back face remained intact after the target deflected $131 \mathrm{~mm}$.

\subsection{Air blast loading of GFRP sandwich composite panels}

A summary of the key results and observations from the air-blast loading of GFRP sandwich panels is given in Table 2. The response of the sandwich composite panel when subjected to 30 $\mathrm{kg}$ charge at two different stand off is compared. When the second panel was subject to a stronger blast a skin crack formed on the front face of the target. Employing DIC was a powerful tool for damage detection and tracking during the blast. The major principal strain fields told the user a great deal about what is happening to the structure during the blast. 
Table 2: Summary of each air-blast conducted on GFRP sandwich panels highlighting the peak pressures, peak strains and visible damage.

\begin{tabular}{llll}
\hline Lay-up/design & $P_{\max }(\mathrm{bar})$ & $\varepsilon_{\max }(\%)$ & Damage \\
\hline $\begin{array}{l}\text { 2x QE1200 skin; } \\
40 \mathrm{~mm} \text { SAN core }\end{array}$ & 2 & 1 & No visible skin damage \\
$\begin{array}{l}\text { 2x QE1200 skin; } \\
40 \mathrm{~mm} \text { SAN core }\end{array}$ & 8 & 3 & $\begin{array}{l}\text { Severe front-skin breakage } \\
\text { and core cracking (no crushing) }\end{array}$ \\
\hline
\end{tabular}

From Figure 6 one can observe the build up of high-strain $\sim 3 \%$ in the central region until a point, where there is a split in the strain field (discontinuity), with some strain relief appearing in a narrow region down the right-hand side of the panel. This region of strain relief indicates a region of separation between the core and skin (where the skin is unsupported by the core), resulting in the load concentrating on the edges of this (cracked-core) region transferring the load through the skin only. The levels of strain observed in the skin along these edges peaked at $\sim 1.8 \%$. The front face was seen to undergo cracking along one edge, this was specifically delamination growth during the compressive phase after or during which some fibres failed (fractured). The origin of the failure is understandable as it is located in the transition region between the two fixed edges of the corner of the plate. This region promotes failure formation. Work has previously been conducted elsewhere [4] investigating the influence and proximity of boundaries to steel plates under such load conditions, yielding similar observations (in terms of deformation and failure origin in this boundary region).

Further analysis into the damage process is shown in Figure 12, which displays the deformed profile of the cross-section across the width of the panel. Out-of-plane displacement of a horizontal central section was taken within the ARAMIS post-processing software and plotted over regular time intervals for the duration of the initial response. It shows the panel deflecting symmetrically about its centre during its 1 st positive stroke up until the point of maximum deflection (occurring at $12.5 \mathrm{~ms}$ ). From these profiles, in particular the return stroke profiles, it is clear that a change in structural balance, or failure, must have occurred within the panel, causing an asymmetric rebound profile of the panel at $15.5 \mathrm{~ms}$. If the trends in the strain data shown previously (in Figure 6) is insufficient, these plots clarify the panel has undergone significant damage. This reinforces the notion of a complete core shear failure, resulting in crack propagation from faceto-face down a significant portion of the panel. The first $1.5 \mathrm{~ms}$ ( 8.0 to $9.5 \mathrm{~ms}$ ) of response show the square wave front of the panel progressing, which is characteristic to impulsive loading situations. After $1.5 \mathrm{~ms}$, there is a faint region of strain relief on one edge of the panel due to crack initiation causing separation between the skin and core (locally) - unsupported skins. Now the core crack formation can be accounted for due to the exaggerated bending stresses experienced in the early stages (around the square wave front) where the radius of curvature in the bend is significantly lower. The reason for the crack developing preferentially on one side rather than the other is due to uneven loading and support conditions experienced (as discussed in the FE analyses). The cubicle design is such that one edge of the composite sandwich panel leads to air (free from obstruction) and one edge leads to the centre of the cubicle and so the magnitude of impulse deteriorates on one side relative to the other (blast wave clearing i.e. the shock wave propagation takes the route of least resistance). This is not an unusual situation for a marine superstructure or a civil engineering structure, which may experience air blast, and therefore consideration of such blast phenomena as well as other shock loading effects is important. 
For the ideal case (with the same support and environment all around the panel) cracks would form from all 4 corners causing a square section of the panel to crack. However, once one crack forms, stress relief dictates that another is unlikely to form without sustained or increased loading. Once the crack formed in the core the front (and back) skins were left unsupported by the core and therefore the strains concentrated on the edges of this core crack and this lead to skin fibre breakage. FE analyses of the front of the steel cubicle and the offset composite sandwich panel in Figure 9 and Figure 10 have shown that the deformation and strain is expected to be biased towards the edge of the target sandwich panel nearest the centre test fixture. This correlated well with the experimental data. The DIC analysis observed the discontinuity in the strain field distribution caused by a separation of skin and core as well as allowed the shifts in the deformed shape to be observed e.g. the deformed profile highlighted in Figure 12. With appropriate experience, DIC can be a very powerful tool for monitoring the structural integrity of various materials and identifying damage mechanisms occurring even when subject to extreme load cases such as these. Sectioning confirmed suspicions from the DIC analysis that failures had occurred, specifically the core crack, which propagated through from face-to-face of the core (see Figure 7).

\subsection{FE modelling of air blasts}

Models were generated to simulate the effects of the boundary conditions on the target response, given they are not constant throughout the duration of blast events. However rigid the sup-

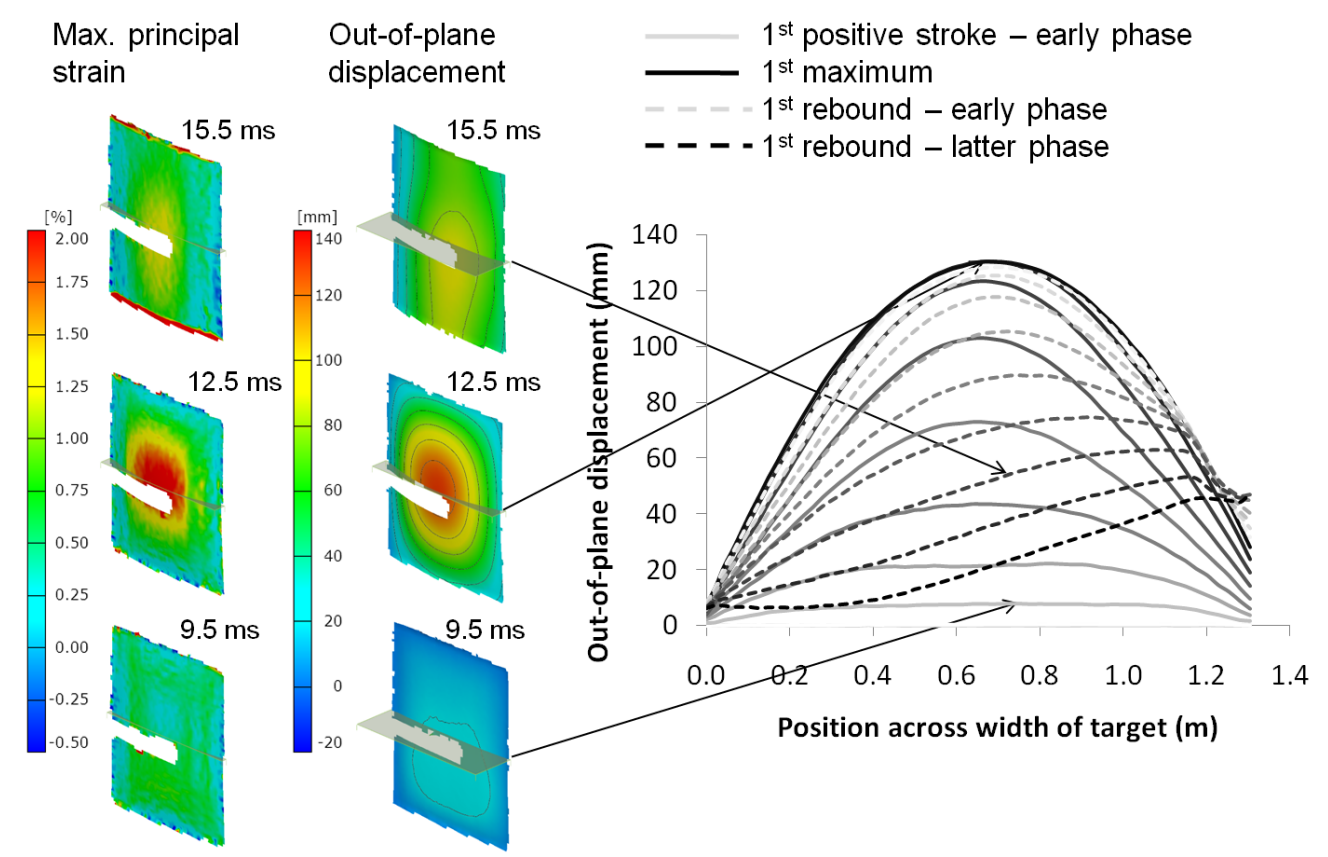

Figure 12: Displacement data taken across a horizontal section running through the point of maximum deflection for the panel (core thickness $40 \mathrm{~mm}$ ) during blast loading (30 kg at $8 \mathrm{~m}$ stand-off). Data displayed for several time intervals from $8 \mathrm{~ms}$ after detonation. Solid lines show displacement profile up to maximum deflection and dotted lines show subsequent return 
port structure is, a degree of elastic deformation is always present, which can affect the response of the target to differing degrees of severity depending on their design. A degree of elasticity can aid the shock resistance of a structure due to the distribution and dissipation of shock energy. This is generally integrated into the design process. Rather than the energy (impulse) going entirely into the front face-sheets of a structure, and moreover rather than all the energy going into the face-sheets in an instant, the target face-sheets are given time to respond. This also allows the local region of the target structure to share the blast energy over the whole structure's system, within limitations of acceptable elastic deformation (a common dynamics design constraint). Fluid mechanical effects of a shock wave interaction with a finite surface are well known, for instance phenomena such as blast clearing, shock wave reflections (superposing) and stiffness of the target can lead to a distinctly non-uniform distribution of the incident impulse. This second and major contributing factor to the response of the target (fluid mechanical effects), often overlooked too, has been neglected from the analysis shown here. Many investigations assume various amounts of symmetry in their models, including the stiffness of the support as well as the distribution of the impulse over the target. This analysis addresses the asymmetry in the support to highlight how the modes of deformation can vary in response. It therefore concentrated on the influence of various degrees of freedom present at the boundaries of the target.

The FE analyses shown ranged from modelling the test cubicle front supporting the plate to the simplified cases of the plate on its own restrained with various boundary conditions. There were several interesting outcomes from these analyses, particularly how the experimental result lay within a range of FE simulation results. The observed experimental boundary conditions lay in between the pinned and fully built-in cases as shown in Figure 11(b-c). Obviously these degrees of freedom can be adjusted to achieve an exact agreement between the experimental and FE simulations and transient boundary conditions can be created using experimental data to represent the stiffness of the cubicle more accurately. However this is not useful information for any user outside of this test facility. Moreover it is seen that the change in impulse will cause the boundary to react differently in both magnitude and frequency, hence the fact that the experimental results lie either side of Case 4 when the impulse is increased from a $30 \mathrm{~kg}$ charge $\mathrm{C} 4$ at $14 \mathrm{~m}$ to $30 \mathrm{~kg}$ charge $\mathrm{C} 4$ at $8 \mathrm{~m}$ stand-off. This set of models simplifies the restraint conditions apparent in real structures and highlights the effects of variable degrees of freedom to material response. The design of the restraint conditions is such a simple tool, which can be used to influence the response of the target and failure modes observed. It could go further and allow favourable locations of failure to be predetermined and, even, help to mitigate the blast effects altogether without failure by dissipating blast energy in the support structures, allowing face sheets time and freedom to absorb energy and deform elastically as discussed earlier. Therefore such support structures can be designed to incorporate such allowable deformation so as to maximise the global response of a structure.

\section{Conclusions}

Effective blast mitigation properties have been demonstrated for lightweight composite sandwich materials as related to full-scale marine and other structures and well instrumented data has been obtained to support this. Advanced strain monitoring techniques (high-speed DIC) were employed to monitor the deformation of the targets during full-scale blasts. Large scale blast testing has proved that full-field displacement and in-plane strain data can be reliably obtained for glass-fibre composite sandwich panels secured around their edge during explosive events. Detailed deformation maps were obtained using DIC under extreme shock loading conditions 
and have been validated by point measurements using a laser gauge system. This full-field deformation and strain data provide for detailed validation of finite element models of large-scale explosive loading of composite sandwich panels. Finite element modelling was used to verify the influences behind the experimental observations such as transient boundary conditions. It was apparent during experimentation that the structural supports are not necessarily fixed during such high rate and impulsive loading events. This relates well to many installations of marine and other structures. Various aspects of blast events have been highlighted by these studies including: the damage that can be sustained and the damage development process; the effect of boundary conditions in terms of type and location of damage sustained and the important role of support configuration for composite panels in blast mitigation. During the air-blast experiments, the damage mode for air blast loaded composite sandwich panels supported around their edge is for a crack to initiate in the front skin (with localised delamination around the cracked region) and shear cracking in the core. This occurs in the transition region from the built in corner to the region where panel flexing can occur as this is where interfacial failure between front skin and the core will occur. The back-face skins maintained their form without sustaining any visible damage such as tearing or cracking. Further research is addressing air and underwater blast loading of carbon-fibre and glass-fibre composite sandwich and laminate structures of varying target geometries.

\section{Acknowledgements}

Much appreciated is the strong support received from Dr Yapa Rajapakse of the Office of Naval Research (ONR N00014-08-1-1151) in particular for Hari Arora. We also appreciate useful discussions with ONR funded and other researchers in the field. We also acknowledge the Metropolitan Police and CPNI for use of the test cubicles and other equipment, GL-group for the use of their facilities and support on site, SP Gurit and PE Composites for provision of materials and GOM UK for support and access to latest DIC equipment during the analysis of the air-blast trial data.

\section{References}

[1] S.B. Menkes and H.J. Opat. Tearing and shear failure in explosively loaded clamped beams. Experimental Mechanics, 13(11):480-486, 1973.

[2] G.N. Nurick and J.B. Martin. Deformation of thin plates subject to impulsive loading - a review, part ii: Experimental studies. International Journal of Impact Engineering, 8(2):171-186, 1989.

[3] G.N. Nurick M.D. Olsson and J.R. Fagnan. Deformation and rupture of blast loaded square plates - predictions and experiments. International Journal of Impact Engineering, 13(2):279-291, 1993.

[4] M.E. Gelman G.N. Nurick and N.S. Marshall. Tearing of blast loaded plates with clamped boundary conditions. International Journal of Impact Engineering, 18(7-8):803-827, 1996.

[5] W.J. Cantwell G.S. Langdon and G.N. Nurick. The blast response of novel thermoplastic-based fibre-metal laminates some preliminary results and observations. Composites Science and Technology, 65:861872, 2005.

[6] G.N. Nurick M.C. Simmons W.J. Cantwell G.S. Langdon, S.L. Lemanski and G.K. Schleyer. Behaviour of fibremetal laminates subjected to localised blast loading: Part i experimental observations. International Journal of Impact Engineering, 34:1202-1222, 2007.

[7] G.S. Langdon M.C. Simmons W.J. Cantwell S.L. Lemanski, G.N. Nurick and G.K. Schleyer. Behaviour of fibremetal laminates subjected to localised blast loading: Part ii experimental observations. International Journal of Impact Engineering, 34:1223-1245, 2007.

[8] S.A. Tekalur, A.E. Bogdanovich, and A. Shukla. Shock loading response of sandwich panels with 3-d woven e-glass composite skins and stitched foam core. Composites Science and Technology, 69(6):736-753, 2009.

[9] S.A. Tekalur, A. Shukla, and K. Shivakumar. Blast resistance of polyurea based layered composite materials. Composites Structures, 84(3):271-281, 2008. 
[10] S.A. Tekalur, K. Shivakumar, and A. Shukla. Mechanical behavior and damage evolution in e-glass vinyl ester and carbon composites subjected to static and blast loads. Composites Part B: Engineering, 39(1):57-65, 2008.

[11] M.S. Hoo Fatt and L. Palla. Analytical modeling of composite sandwich panels under blast loads. Journal of Sandwich Structures and Materials, 11(4):357-380, 2009.

[12] E.H. Wang and A. Shukla. Analytical and experimental evaluation of energies during shock loading. International Journal of Impact Engineering, 37(12):1188-1196, 2010.

[13] M. Jackson and A. Shukla. Performance of sandwich composites subjected to sequential impact and air blast loading. Composites Part B: Engineering, 2011. In Press.

[14] SP Gurit. Material data sheets. www.gurit.com, 2011

[15] J.M. Biggs. Introduction to Structural Dynamics. McGraw-Hill Book Company, 1964.

[16] P.D. Smith and J.G. Hetherington. Blast and ballistic loading of structures. Butterworth Heinmann, 1994. 